\title{
Feeding behavior and visual field differences in loggerhead and leatherback sea turtles may explain differences in longline fisheries interactions
}

\author{
Natasha Warraich ${ }^{1,2}$, Jeanette Wyneken ${ }^{1, *}$, Nicholas Blume ${ }^{3,4}$ \\ ${ }^{1}$ Department of Biological Sciences, Florida Atlantic University, Boca Raton, Florida 33431, USA \\ ${ }^{2}$ Florida Fish and Wildlife Conservation Commission, West Palm Beach, Florida 33412, USA \\ ${ }^{3}$ College of Business, Florida Atlantic University, Boca Raton, Florida 33431, USA \\ ${ }^{4}$ Division of Student Affairs and College of Undergraduate Studies, Nova Southeastern University, Fort Lauderdale, \\ Florida 33314, USA
}

\begin{abstract}
Loggerhead Caretta caretta and leatherback Dermochelys coriacea sea turtles are caught frequently as longline bycatch. Loggerhead turtles are often hooked in the mouth, while leatherbacks often are hooked in the shoulder or flippers. Comparisons of feeding behavior and accuracy in biting surrogate 'prey' targets, in the presence of waterborne food odors, identified species-specific differences that may predispose the turtles to be hooked differently. Additionally, the visual fields of post-hatchling loggerhead and leatherback sea turtles were measured and compared to determine if field of view could further contribute to feeding behavior differences and refining the explanation as to why the 2 species are hooked differently. We found that loggerhead turtles, which have a larger visual field and a small area of binocular vision, were more accurate when biting a target than leatherbacks. These traits may explain their greater incidence of mouth, throat, and stomach hookings. Leatherback turtles have a smaller field of view and no overlap of visual fields, and they were less accurate in apprehending targets. Leatherbacks lack binocular vision, which might explain why they are prone to entanglement or hooking external to the mouth more often than loggerheads. Together, visual field and biting accuracy may help explain why leatherbacks and loggerheads differ in how they interact with fishing lines and the locations of their hookings. Such understanding of the species' behavior and limits of visual fields is essential for formulating further bycatch reduction approaches.
\end{abstract}

KEYWORDS: Sea turtle $\cdot$ Dermochelys coriacea $\cdot$ Caretta caretta $\cdot$ Bycatch $\cdot$ Feeding $\cdot$ Binocular vision

\section{INTRODUCTION}

Fisheries bycatch is a significant source of mortality for sea turtles, sharks, seabirds, and other nontarget species worldwide (Lewison et al. 2004a, Wallace et al. 2013). Such mortality is significant and contributes to the decline (and prevents recovery) of these imperiled species (Wallace et al. 2013). The main target species of longline fiheries are commer-

\footnotetext{
${ }^{*}$ Corresponding author: jwyneken@fau.edu
}

cially valuable fish such as tuna (Thunnus spp.), swordfish Xiphias gladius, and mahi mahi Coryphaena hippurus (summarized by Lewison \& Crowder 2007). Fisheries bycatch is a major anthropogenic stressor on marine ecosystems (Baum \& Myers 2004, Dunn et al. 2011, Lewison et al. 2014). Davis (2002) estimated that one quarter of all fisheries catch worldwide is bycatch. Lewison et al. (2014) emphasized that fisheries can impact large predator abun-

() The authors 2020. Open Access under Creative Commons by Attribution Licence. Use, distribution and reproduction are unrestricted. Authors and original publication must be credited. 
dance (including marine turtles) both via direct capture and indirectly through incidental capture of nontarget species or bycatch. Mortality from longline bycatch is implicated in the decline of several sea turtle species in the Atlantic and Pacific Oceans (Spotila et al. 2000, Piovano et al. 2004, Lewison \& Crowder 2007, Wallace et al. 2013, Fossette et al. 2014). Studies of the behavior that predisposes the turtles to being hooked tend to focus on the coincidence of overlapping habitats (Polovina et al. 2000, Fossette et al. 2014, Stewart et al. 2016), but not on aspects of the behavior predisposing them to different hookings.

Loggerhead Caretta caretta and leatherback Dermochelys coriacea sea turtles are caught incidentally on longlines (Lewison et al. 2004a, Watson et al. 2005, Foster et al. 2012). These individuals are often large immature or adult animals that represent future recruitment to the reproductive segment of populations (Wallace et al. 2008). Although bycatch of sea turtles may be rare for individual fishers, the cumulative numbers of hooks deployed can have a substantial impact on the population (Lewison et al. 2004b, Coelho et al. 2015). When the 2 species interact with longlines, they tend to do so somewhat differently. Leatherbacks tend to become entangled in the gear, getting hooked externally (i.e. 'foul hooked') or, less often, swallow the hooks. Loggerheads are less often entangled and are more often hooked in the mouth, throat, or stomach (Casale et al. 2008, Epperly et al. 2012, Foster et al. 2012, Coelho et al. 2015). Effects of hookings can range from slight injury, to delayed mortality following release, to death on the line. Cumulatively, such direct and delayed losses negatively impact population recovery (Lewison et al. 2004a, Donoso \& Dutton 2010, Alfaro-Shigueto et al. 2011, Swimmer et al. 2012).

Several advances have been made to reduce sea turtle bycatch, such as time fished, bait type used, hook type (circle vs. J-hooks) and barb offset, and bait soak times (Shiode et al. 2005, Watson et al. 2005, Gilman et al. 2006, Lucchetti \& Sala 2010, Santos et al. 2012, Stokes et al. 2012, Swimmer at al. 2017). Yet understanding why the interactions of these 2 species with longlines differ remains focused on the descriptions of the hooking locations and consequences; there has been less investigation of behavioral causes. A common assumption is that both species are attracted to bait on the hook (e.g. squid, mackerel) or in-water lights. Loggerheads are attracted to lights on the lines (Wang et al. 2007), but leatherbacks are not (Gless et al. 2008). When the turtles attempt to eat the bait, they become caught or entangled (Watson et al. 2005, Southwood et al. 2008,
Stokes et al. 2011, Gilman \& Huang 2017). To better understand how and why sea turtles are caught, and focus bycatch reduction techniques, studies of behavior that leads to incidental capture, particularly feeding behavior, are needed. When loggerhead and leatherback sea turtles are hunting for food in a laboratory setting, they explore their tanks, pause swimming when a food odor is detected, then reorient toward the food once it is seen. Loggerheads often open their mouths prior to reaching their prey (Guzman 2008, authors' unpubl. obs.) while leatherbacks bite at prey immediately before making contact (authors' unpubl. obs.).

Worldwide, efforts have been made to reduce sea turtle bycatch for a variety of fisheries and gear types (Garrison 2005, Kaplan 2005, Gilman et al. 2006, Kerstetter \& Watson 2006, Swimmer \& Brill 2006, Foster et al. 2012, Santos et al. 2012, Wallace et. al 2013). These efforts include changing the bait types to decrease the likelihood of interactions with sea turtles. Several studies found that the bycatch of sea turtles decreased significantly with the use of fish bait rather than squid (Foster et al. 2012, Santos et al. 2012, Swimmer et al. 2017). Altering the type of hook is another technique to reduce bycatch. Historically, Jhooks have been used in many longline fisheries globally; in the longline fisheries of the USA and some other countries, there is an ongoing push toward using circle hooks that are less prone to foulhooking or mouth-hooking sea turtles and other bycaught species (Witzell 1999, Polovina et al. 2003, Cambiè et al. 2012, Santos et al. 2012). Watson et al. (2005) identified reduced leatherback bycatch when baits were switched from squid to mackerel and when using circle hooks rather than J-hooks. While overall bycatch of leatherbacks was reduced using circle hooks, the occurrence of leatherbacks hooked in the mouth rather than foul-hooked increased by $\sim 20 \%$ when baits were rigged with circle hooks (Epperly et al. 2012). Foul hookings were still the most common bycatch interaction for leatherbacks with either hook type (Epperly et al. 2012, Foster et al. 2012, Stokes et al. 2012). Bycatch remains a significant source of interaction for loggerheads and leatherbacks even in fleets using suggested hook and bait combinations (Wallace et al. 2013). The persistence of this problem suggests that the feeding behavior of sea turtles is not sufficiently understood.

Most bycaught loggerheads tend to be hooked in the mouth or internally in the throat, stomach, or intestines (Gilman et al. 2006). In contrast, most bycaught leatherbacks are foul-hooked or entangled in the gear (Epperly et al. 2012, Swimmer et al. 2017). 
Both species may be attracted to the area of the longline sets by visual and chemical stimuli from the baits and gear, or a combination of those factors (Wang et al. 2007, Gless et al. 2008, Southwood et al. 2008). Yet, the fact that leatherbacks are foul-hooked and less frequently recorded as ingesting the bait (Gilman et al. 2006, Gless et al. 2008), whereas loggerheads often ingest the bait, suggests fundamental differences in feeding behavior.

The main goal of this study was to investigate if species-specific feeding behavior and visual fields can explain the differences in the nature of bycatch. We tested how loggerheads and leatherbacks responded to surrogate bait or prey objects suspended in the water by measuring biting attempts. Additionally, to identify if there are visual field differences that might relate to either propensity to be foulhooked or ingest baits, we mapped and compared the visual fields of the 2 species. Both lines of data identified some differences and may provide an explanation for why leatherbacks are hooked externally more often while loggerheads are hooked in the mouth, throat, or stomach.

\section{MATERIALS AND METHODS}

\subsection{Collection and maintenance}

Hatchling loggerhead and leatherback sea turtles were collected upon emergence from nests laid in southeastern Florida (USA) beaches (Palm Beach County; $26.34^{\circ} \mathrm{N}, 80.07^{\circ} \mathrm{W}$ to $\left.26.87^{\circ} \mathrm{N}, 80.05^{\circ} \mathrm{W}\right)$. Turtles were transported in covered Styrofoam ${ }^{\mathrm{TM}}$ boxes with damp sand at the bottom to Florida Atlantic University's Marine Lab at Gumbo Limbo Environmental Complex in Boca Raton, a trip of less than $60 \mathrm{~min}$. Approximately $10 \%$ of a clutch (10 loggerheads clutch ${ }^{-1}$ and 5 leatherbacks clutch ${ }^{-1}$ ) were selected for potential inclusion in the study. The turtle numbers collected were defined by protocols for a separate, unrelated study for which they were used following this study. All hatchlings selected were morphologically normal (species-typical shell shape, scute patterns for loggerheads, normal head and flippers, no skin lesions) and underwent a 5-10 d quarantine observation process before entering the colony to ensure that they were healthy. Any signs of sluggish swimming or diving behavior or failure to feed was viewed as abnormal and precluded the animals from being used in this study. The turtles were monitored daily throughout the study to ensure that they were swimming and feeding normally.
Each turtle was measured weekly for straight carapace length (SCL) and width to the nearest $0.1 \mathrm{~mm}$ with Vernier calipers, and weighed to the nearest $0.1 \mathrm{~g}$ using an electronic scale to track normal growth as a proxy for ensuring that the turtles were healthy throughout the study. Turtles selected for the study from those passing quarantine were $4-7 \mathrm{wk}$ old. Loggerheads averaged 54.1-62.1 mm SCL and leatherbacks averaged 74.0-82.7 mm SCL during the study.

Loggerheads were kept in tanks with open flowthrough seawater at $25-29^{\circ} \mathrm{C}$ and were held individually in flow-through floating baskets $(19.5 \mathrm{~cm} \times$ $12.7 \mathrm{~cm} \times 12.7 \mathrm{~cm}$ ) to prevent social hierarchies. Leatherbacks were housed individually in tanks filled with filtered seawater, at $23-25^{\circ} \mathrm{C}$. Because leatherbacks do not recognize barriers such as tank walls, each was on a tether made of a $1.0 \mathrm{~cm}^{2}$ hook and loop patch attached to the carapace with a drop of cosmetic-grade cyanoacrylate cement. The loop side of the patch served as the attachment site for a hook-side patch leading to a monofilament tether that was approximately $16-20 \mathrm{~cm}$ in length. The tethers allowed the turtles to swim and dive in any direction but prevented abrasions caused by repeated contact with the sides or bottom of the tank. Both species were kept on a 12:12 h light:dark cycle, with light supplied by overhead UVA/UVB fluorescent lamps (ReptiSun ${ }^{\circledR} 5.0$ or 10.0) located $0.5 \mathrm{~m}$ above the water.

\subsection{Visual fields}

To determine if loggerheads and leatherbacks differ in their visual fields, which can affect feeding behavior, we measured the mean angles of view of each turtle. Dorsal, frontal, lateral, and ventral photos (Fig. 1) were taken of 10 loggerheads and 5 leatherbacks using a Canon Powershot (model ELPH 180), with the camera lens positioned $20 \mathrm{~cm}$ from each turtle for all photos. We measured 1 eye per turtle because the eyes are bilaterally symmetrical. The frontal and ventral views were measured on whichever eye was fully open. Lateral views were used to describe pupil shape and ensure the pupil was approximately centered as the standardized position for our measurements. To assess potential overlap of visual field, we geometrically mapped the maximum visual angles from each eye. Field of view angles were then measured from the pupil edges to the center of the lens as the vertex (adapted from McComb \& Kajiura 2008, Lisney et al. 2012). This procedure was used to find the anterior-posterior 


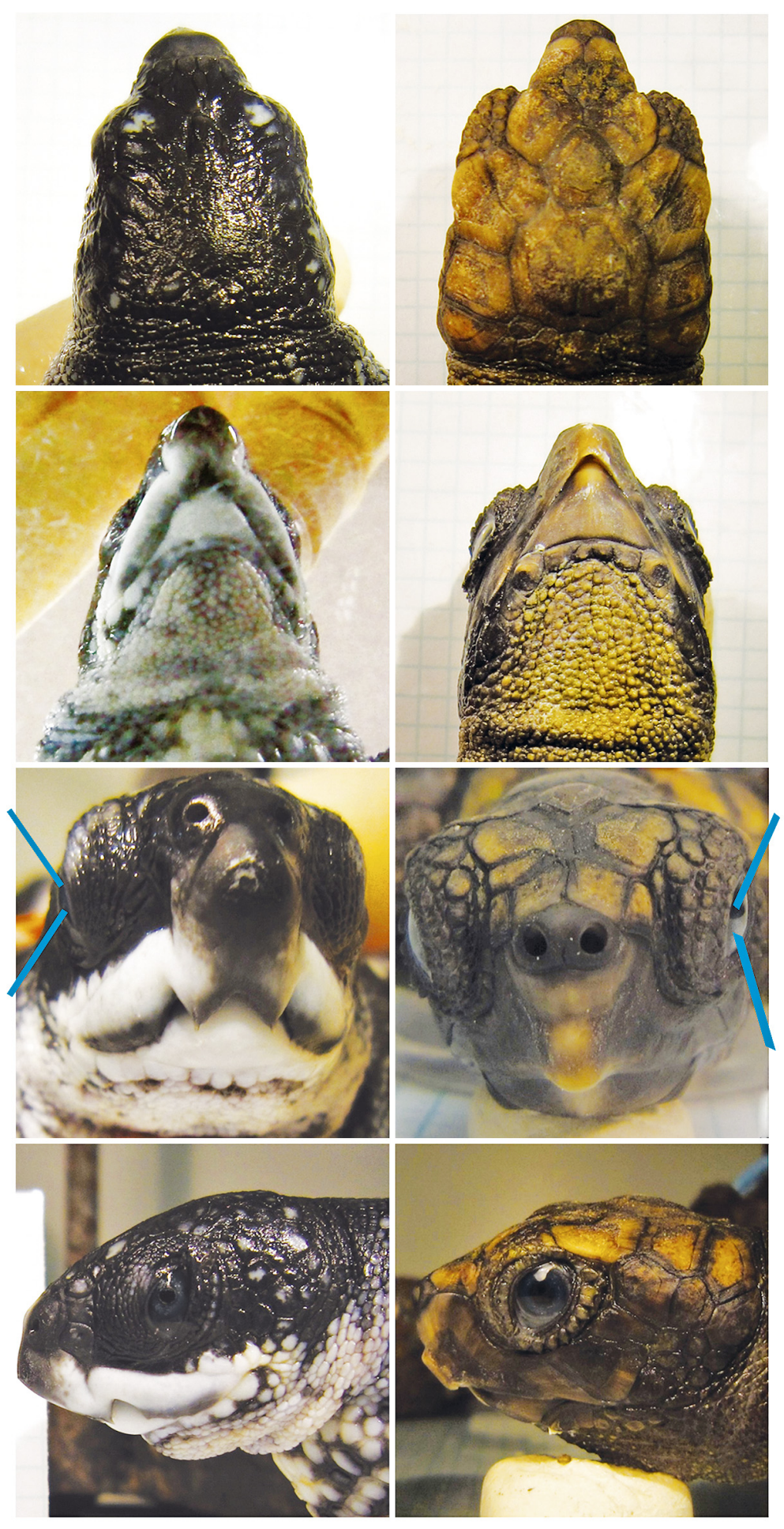

Fig. 1. Photos of leatherbacks (left column) and loggerheads (right column) used to map the visual fields. From top: dorsal, ventral, frontal, and lateral views. Note that the eye is not visible in dorsal view due to the upper lid. This morphological structure blocks a dorsal component to the field of view near the head. The frontal view allows mapping of the maximum dorsal-ventral arc (blue lines), and the lateral and ventral views allow mapping of the maximum anterior-posterior arc (see Fig. 4) and identification that the field of view extends ventrally and dorsal-ventral measures. We inferred bilateral symmetry in calculating visual field overlap.

We estimated the fields of view for each species using frontal, ventral, and lateral views. The tangents of the mean angle measurements were used to estimate the lengths of the major and minor axes, where $a$ and $b$ are the major and minor axes, respectively. We calculated an elliptical field $(y)$ defining the extent of the visual field as:

$$
y= \pm \sqrt{\left[1-\frac{(x-p)^{2}}{a^{2}}\right] b^{2}}+q
$$

where $(p, q)=(0,0)$

We next calculated the area of ellipses at $20 \mathrm{~cm}\left(y_{20}\right)$ for each species:

$$
y_{20}=\Pi a b
$$

\subsection{Bite propensity and bite accuracy trials by species}

To determine how the species differed in their feeding behavior and bite accuracy (bite performance), we conducted visual approach trials in which turtle behavior in the presence of a surrogate 'food' model was measured. Trials were conducted in a rectangular $(85 \mathrm{~cm} \times 60 \mathrm{~cm} \times 57 \mathrm{~cm})$ tank (Fig. 2) filled with 2221 of filtered seawater at the same temperature as the turtle's housing tank water. A mirror measuring $63.5 \times$ $76 \mathrm{~cm}$ was placed at a $45^{\circ}$ angle in the tank to allow concurrent observation of the lateral and ventral views of the animal. Each turtle's trial was filmed from a fixed location using a high-definition video camera (Canon, Model Vixia) mounted on a tripod.

Between trials, the test tank was drained and cleaned with fresh water and $\mathrm{VedCo}^{\mathrm{TM}}$ D-256 disinfectant solution, and then rinsed with freshwater before refilling the tank with filtered seawater. Target stimuli were also disinfected and rinsed similarly between trials.

Turtles were tested individually with standardized surrogate bait targets and bait odors. Each turtle was tethered in the center of the tank with thin monofilament ( 20 \pm $2 \mathrm{~cm}$ in length) to a Lycra ${ }^{\circledR}$ harness for log- 

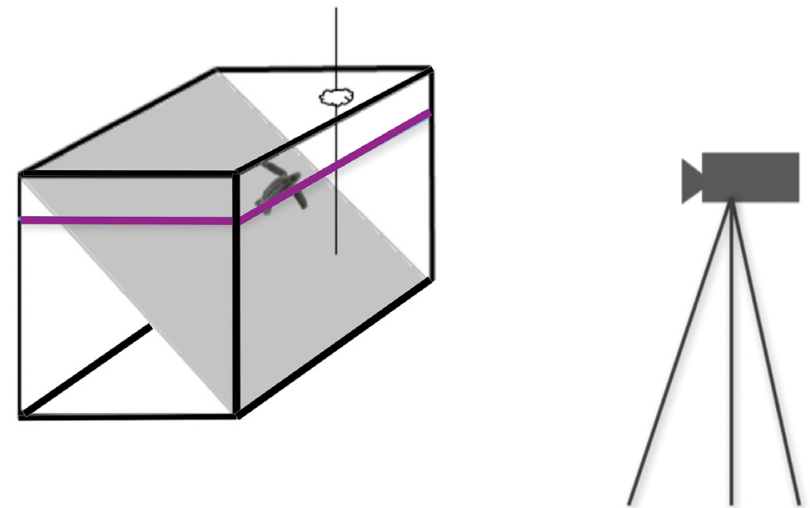

Fig. 2. Test tank set-up for biting trials, with mirror (in grey) at a $45^{\circ}$ angle in the water (purple line). The test target is diagrammed as the oblong shape in the vertical line. The turtle's tether from above is not shown. This test configuration allowed us to view the animal's ventral and lateral movements simultaneously while the test target was lowered into the water.

gerheads (after Salmon \& Wyneken 1987) and a Velcro ${ }^{\circledR}$ patch for leatherbacks. Turtles were fasted the day prior to and the day of their trial. Each turtle was given a 30 min acclimation period, after which a 3 min control period began. At the beginning of the control period, $20 \mathrm{ml}$ of filtered seawater were introduced to the tank immediately and a standardized visual stimulus was lowered into the water (Fig. 3). At the end of the control period, the standardized visual stimulus was raised out of the water, and the 3 min experimental period began. At the start of the experimental period, a bait odor stimulus was added to the water and the visual stimulus was lowered into the water again. The visual stimulus represented an odor-free, surrogate 'prey' for the turtle. We tested a small and a large stimulus. The small visual stimulus (hereafter, small target) was a silver and grey lead fishing weight (no. 3 'split-shot' lead weight, $1 \mathrm{~cm}$ diameter; Fig. 3). A pink and taupe colored plastic jellyfish (hereafter, jellyfish model) served as the large visual stimulus $(11 \mathrm{~cm}$ in diameter, $12 \mathrm{~cm}$ in maximum length, $22 \mathrm{ml}$ volume;
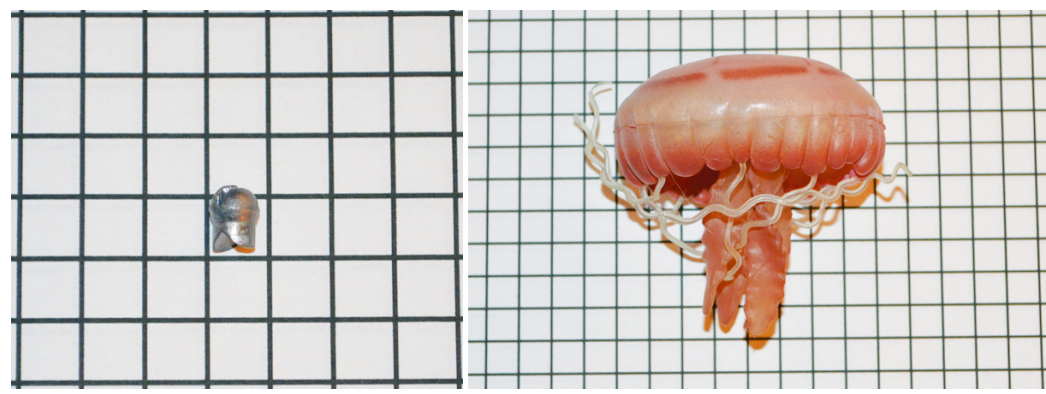

Fig. 3. Small target (split-shot lead weight; left) and jellyfish model (right) were used in biting behavior trials. Photos show these visual targets against a $1 \mathrm{~cm} \times 1 \mathrm{~cm}$ grid
Fig. 3) following the methods used by Constantino \& Salmon (2003). The researcher stood, with minimal movement, in the same position aside the tank for all control and experimental periods.

The numbers of turtles tested that bit at the targets were compared between the species by target size. For both loggerhead and leatherback turtles, bite performance was measured in several ways: (1) total bites during control or experimental periods (defined as total bite performance), (2) total bites at the visual stimulus, (3) total successful bites (a bite in which the turtle's mouth made contact with the target), and (4) initial bite success (if the turtle succeeded in biting the stimulus on its first attempt). Additionally, we quantified if the bite response was elicited by a stationary or moving visual stimulus. For loggerheads, we compared if the turtles differed in their responses to the 2 stimuli.

\subsubsection{Loggerhead bite propensity and accuracy tests}

The small target (Fig. 3) was affixed to a piece of $5.4 \mathrm{~kg}$ strength (12 lb test) monofilament line and lowered to approximately $5 \mathrm{~cm}$ below the water surface field of view of the turtle. The line suspending the stimulus was held taut with a $170 \mathrm{~g}$ weight on the tank bottom to keep the stimulus steady in the water. A trial began when $20 \mathrm{ml}$ of filtered seawater (control) or $20 \mathrm{ml}$ of squid odor (test solution) were introduced into the test tank from above via a $20 \mathrm{ml}$ syringe. The squid odor solution was prepared by soaking $120 \mathrm{~g}$ of thawed squid in $1 \mathrm{l}$ of filtered sea-

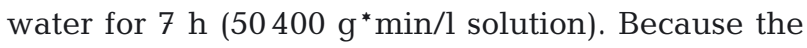
control treatment consistently resulted in lack of response, it was discontinued after 10 turtles showed no response. Ten loggerheads were tested with a control and squid odor solution; 13 were tested with squid odor alone (23 total loggerheads). If a turtle received the control treatment, it was also tested with squid odor. The seawater control was always introduced before the test odor. After introduction of the control or test solution, the visual target was lowered into the test tank. Behavior was recorded for $1 \mathrm{~min}$ once the turtle bit at the visual stimulus or a total of $3 \mathrm{~min}$ if the turtle did not bite at the stimulus during the first minute. If the odor treatment was delivered after the control treatment, the target was lifted out of the water, 
squid odor was introduced into the tank, and then the visual target was then lowered back into the tank.

All loggerheads were tested with stationary and moving surrogate baits to ascertain if a moving target changed the turtle's responses. A moving target was created by gently pushing the line that the stimulus was attached to in order to make it sway a few $\mathrm{cm}$ in the water.

The jellyfish model was used as a visual target for 10 loggerheads using a seawater control and squid odor. The jellyfish model was attached to the middle of a vertical monofilament line, $20 \mathrm{~cm}$ in length, and was made negatively buoyant with a lead fishing weight. The upper surface of the jellyfish model was approximately $3 \mathrm{~cm}$ below the water surface. The odors were delivered in the same manner as trials performed with the lead split-shot target. A trial was concluded once the animal made an attempt to bite the visual target. If the turtle did not try to bite at the visual target, the trial was concluded after $3 \mathrm{~min}$.

\subsubsection{Leatherback bite propensity and accuracy tests}

The visual target for leatherbacks was the jellyfish model (no leatherbacks approached the small target). Homogenized lion's mane jellyfish Cyanea capillata was used as the odor stimulus to elicit feeding behavior in leatherbacks (after Constantino \& Salmon 2003). A trial began when $20 \mathrm{ml}$ of filtered seawater (control) or $20 \mathrm{ml}$ of homogenized lion's mane jellyfish odor were introduced into the test tank. If a turtle received the control treatment, it also was tested with lion's mane odor. The control was always introduced before the odor. After introduction of the control or odor, the visual target was lowered into the test tank. Behavior was recorded for $1 \mathrm{~min}$ once the turtle bit at the visual stimulus or for $3 \mathrm{~min}$ if the turtle did not bite at the stimulus. The treatments were delivered in the same method as for loggerheads. All animals were tested with a stationary and a moving visual stimulus to ascertain if there was a preference for one over the other. Thirteen leatherbacks were tested with a seawater control and jellyfish odor, and 14 with lion's mane jellyfish odor alone (27 total leatherbacks).

\subsection{Statistical analyses}

All variables (total bite performance, total bites at the visual target, total successful bites, initial bite success, and bite response to moving vs. stationary targets) were compared between control and experimental periods using Wilcoxon signed rank tests (Zar 1998). Relative flipper stroke rate changes and bites per test period were compared between loggerheads and leatherbacks using a Mann Whitney U-test. Results were considered significant at $\mathrm{p}<0.05$. All analyses were performed using Minitab ${ }^{\circledR} 16$ statistical software.

\section{RESULTS}

Sample sizes varied by treatment (Loggerheads: $\mathrm{n}=23$ small target, $\mathrm{n}=10$ jellyfish model; leatherbacks: $n=27$ ), because some animals qualified for release as part of a different, unrelated study, and because some treatments resulted in no response. When not being tested, all animals used in this study were fed on in-house manufactured diets that did not contain any of the test fish, squid, or jellyfish. Leatherbacks often missed apprehending their food and required several attempts. Loggerheads rarely missed apprehending their food.

Normal feeding behavior in hatchling loggerhead and leatherback sea turtles involves the animals actively searching for food after initially pausing their swimming when the food odor is detected. Loggerheads actively search for food at the surface or on the bottom of their holding tank, increase flipper stroke rate to get to food, dive towards the food, and bite at food or surface bubbles after a brief pause in swimming. Leatherbacks pause briefly in their swimming when they detect food, orient towards the food, increase flipper stroke rate to approach, and bite at it.

\subsection{Visual field}

Field of view analyses by species ( $\mathrm{n}=10$ loggerheads and 5 leatherbacks) showed that the visual field did not extend dorsally in either species due to the extent of the upper eyelid and orbit margins. In both species, the maximum anterior-posterior and dorsalventral axes were used to characterize the maximum aspects field of view, and an asymmetrical ellipse with a very short upper half of the minor axis described the shape of the field of view (Fig. 1). Leatherback turtles have a relatively smaller field of $3550 \mathrm{~cm}^{2}$ and no overlap of visual fields (Fig. 4A). Consequently, leatherback turtles lack binocular vision. The loggerhead turtle field of view is relatively large and, based upon mirror image mapping of left and right eyes, overlaps approximately $60^{\circ}$ anterior to the snout (Fig. 4B), indicating a small area of binocular vision. The estimated 


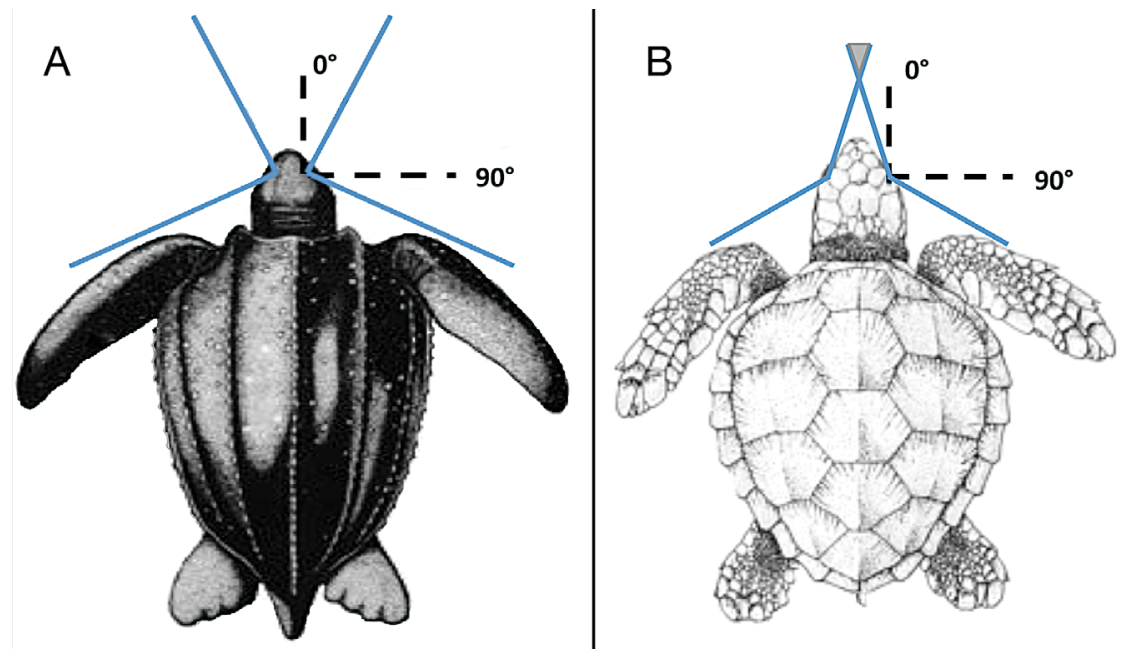

Fig. 4. Anterior-posterior ranges of visual fields extending laterally from the eyes in (A) leatherback and (B) loggerhead turtles. Sagittal $0^{\circ}$ axes and orthogonal $90^{\circ}$ axes were overlaid on images of each eye for reference when mapping the field. The visual field overlap, where binocular vision occurs, is in grey anterior to the snout. Lack of overlap in the leatherback visual fields indicates no depth perception. Sketches were modified from their sources (leatherback: USFWS Fact Sheet 1970; loggerhead: Dodd 1988)

Table 1. Summary of leatherback and loggerhead biting results ( $\%$ of turtles that bit at a target and the number of bites) in the laboratory. Mann-Whitney $U$-tests were used to compare the number of bites

\begin{tabular}{|c|c|c|c|c|}
\hline Test condition & $\begin{array}{l}\text { \% Loggerheads } \\
\text { (no. bites) }\end{array}$ & $\begin{array}{l}\% \text { Leatherbacks } \\
\text { (no. bites) }\end{array}$ & $U$ & $\mathrm{p}$ \\
\hline \multicolumn{5}{|l|}{ Control } \\
\hline Small target & $10(1)$ & $0(0)$ & & \\
\hline Jellyfish model & $20(10)$ & $7.7(8)$ & & \\
\hline \multicolumn{5}{|l|}{ Experimental } \\
\hline Small target & 73.9 (199) & $0(0)$ & 430.0 & 0.02 \\
\hline Jellyfish model & $60(37)$ & $44.4(147)$ & 158.5 & 0.43 \\
\hline \multirow{5}{*}{$\begin{array}{l}\text { Stationary vs. } \\
\text { moving target }\end{array}$} & 20 (16 stationary) & & 430.0 & 0.28 \\
\hline & $\begin{array}{l}\text { vs. } 50 \text { ( } 21 \text { moving) } \\
\text { No preference - } \\
\text { jellyfish model }\end{array}$ & & & \\
\hline & & 37 (126 stationary) & 252.5 & 0.05 \\
\hline & & $\begin{array}{l}\text { vs. } 2 \text { of } 27 \text { (9 moving) } \\
\text { Preferred stationary }\end{array}$ & & \\
\hline & $\begin{array}{c}26 \%(119 / 201 \text { bites }) \\
\text { were at moving target - } \\
\text { small target }\end{array}$ & $\begin{array}{c}37 \% \\
\text { (126/135 bites) were } \\
\text { at stationary target - } \\
\text { jellyfish model }\end{array}$ & 456.0 & 0.0005 \\
\hline
\end{tabular}

head bit at the small target (lead split-shot), and only 1 leatherback and 2 loggerheads bit the jellyfish model. During the experimental periods, both species bit at targets. Consequently, only experimental period results were informative in assessing target approach behavior and comparing bite accuracy of the turtles.

When presented with the small target, there was a distinct difference between the species $(U=$ 430, $\mathrm{p}=0.02)$. No leatherback (0 of 5 turtles) showed any interest and none bit the target. Consequently, no additional leatherbacks were tested with the small target. In contrast, loggerheads bit at the small target (17 of 23 turtles; 199 total bites, mode $=5$, range $=3-20$ ) .

Both species bit the jellyfish model, and there was no difference in total bites $(U=158.5, \mathrm{p}=$ 0.43). Twelve of 27 leatherbacks bit the model; they mostly bit the bell portion (147 total bites, mode $=7$, range $=1-31$ ). Six of 10 loggerheads approached and somewhat tentatively bit, mostly the tentacles (37 total bites, mode $=5$, range $=2-15$ ). Loggerheads bit more often during the experimental periods than during the control periods $(U=430$, $\mathrm{p}=0.02$ ) and showed no preference for biting small vs. large targets $(U=71, \mathrm{p}=0.09)$.

In terms of bites directed at the targets, leatherbacks only bit at the jellyfish model. Loggerheads and leatherbacks did not differ in area of the 2 ellipses, at $20 \mathrm{~cm}$ from each eye (a standard distance used in this study) was $11278 \mathrm{~cm}^{2}$ for loggerhead sea turtles.

\subsection{Bite accuracy}

During the control periods, the turtles seldom showed any response to a visual target; 1 logger-
Table 2. Summary comparing the percent of leatherbacks and loggerheads that bit at a target and the number of bites at targets during the experimental period. Mann-Whitney $U$-tests were used to compare the number of bites

\begin{tabular}{|lcccc|}
\hline & $\begin{array}{c}\text { \% Loggerheads } \\
\text { (no. bites) }\end{array}$ & $\begin{array}{c}\text { \% Leatherbacks } \\
\text { (no. bites) }\end{array}$ & $U$ & $\mathrm{p}$ \\
\hline $\begin{array}{l}\text { Small target } \\
\text { Jellyfish model }\end{array}$ & $60(253)$ & $0(0)$ & 411.5 & 0.05 \\
\hline
\end{tabular}


Table 3. Summary of successful leatherback and loggerhead bites during experimental periods with a jellyfish model. Only the jellyfish model results were used to compare if there was a significant difference between species. MannWhitney $U$-tests were used to compare the number of bites

\begin{tabular}{|lcccc|}
\hline & \% Loggerheads & \% Leatherbacks & $U$ & $\mathrm{p}$ \\
\hline First bite accuracy & $\begin{array}{c}60 \\
\text { (successful on } \\
\text { first bite) }\end{array}$ & $\begin{array}{c}22 \\
\text { (successful on } \\
\text { first bite) }\end{array}$ & 54.0 & 0.10 \\
$\begin{array}{l}\text { Total successful bites } \\
\text { Jellyfish model }\end{array}$ & $\begin{array}{c}50.6 \\
\text { (37 of } 73 \text { bites) }\end{array}$ & $\begin{array}{c}58.5 \\
\text { (86 of } 147 \text { bites) }\end{array}$ & 118.5 & 0.66 \\
\hline
\end{tabular}

the number of bites directed at the jellyfish model (Table 1), and loggerheads did not differ significantly in the number of times they bit at the small target vs. the jellyfish model (Table 2). Neither first bite success nor total bite success differed in any measure between species (Table 3).

When presented with a stationary vs. a moving target, loggerheads showed no preference (Table 1, $U=$ $430, \mathrm{p}=0.28)$. Leatherbacks bit at stationary targets more often than moving ones (Table 1, $U=252.5, \mathrm{p}=$ 0.05). Loggerheads were more likely to bite at a small moving target, while leatherbacks were more likely to bite a large stationary target (Table $1, U=456, \mathrm{p}=$ 0.0005).

\section{DISCUSSION}

Several approaches are used to reduce sea turtle bycatch in fisheries worldwide (Kerstetter \& Watson 2006, Gilman \& Huang 2017, Swimmer et al. 2017). A common approach is to change the bait and hook type to decrease bycatch, although some time-area fisheries closures are also implemented. Many fisheries have switched from J-hooks to circle hooks (Santos et al. 2012). Circle hooks with no or minimal offset and wider circles make it more difficult for sea turtles or other common bycatch species to become hooked (Witzell 1999, Cambiè et al. 2012, Santos et al. 2012, Gilman \& Huang 2017). Circle hooks rigged in squid bait also reduced the proportion of leatherbacks caught compared to J-hooks (Watson et al. 2005, Gilman \& Huang 2017, Swimmer et al. 2017), yet leatherback mouth hookings increased by $~ 20 \%$ when baits were rigged with circle hooks. Foulhookings and entanglement were still the most common for leatherbacks with either hook type (Epperly et al. 2012, Foster et al. 2012, Stokes et al. 2012,
Gilman \& Huang 2017, Swimmer et al. 2017). These results suggest that the increase in proportion of mouth hooking with circle hooks may be caused by the reduced propensity for a circle hook to snag the turtle externally. Based upon our observation that leatherbacks lack depth perception, and that in the lab they frequently make multiple approaches toward their food before successfully biting it, we hypothesize that when the hook barb is contained within the bait, the turtles are less likely to become foul-hooked. However, they may re-approach the baited hook, and if they successfully bite and ingest the bait, they then may become hooked in the mouth. Leatherbacks may become externally hooked more frequently, simply as a consequence of their more limited visual fields and lack of binocular vision. Leatherback turtles have a smaller elliptical field of view than loggerheads, and no overlap of visual fields, and hence monocular vision, which limits visual depth perception. Leatherbacks may bite near baits (and other targets, such as our lab jellyfish model showed) but miss; repeated attempts may lead to greater potential for becoming entangled in lines or foul hooked.

Loggerhead turtles have a large and a small area of overlapping visual fields. The overlap indicates the loggerheads have some binocular vision, which may explain their greater accuracy in biting baited hooks (as well as the small targets and the jellyfish models' tentacles in the laboratory). Because loggerheads have greater success in apprehending targets, they are likely more successful in catching baits; the more frequently a turtle gets a bait in its mouth, the greater the opportunity to be mouth-hooked or to swallow the hooks.

We found that leatherbacks only bit the larger target (jellyfish model), completely ignoring the small target. Further, they only bit the bell portion of the target and bit a few times. This behavior is consistent with feeding strategies for maximizing energy intake of high volumes of low-calorie prey (Fossette et al. 2012, Heaslip et al. 2012). When tested with the smaller target, the leatherbacks behaved as if it was not there. Single small prey items may not be energetically 'worthwhile' unless they are highly concentrated and abundant (Heaslip et al. 2012).

In general, loggerheads tend to bite a variety of food types in nature (Marshall et al. 2012). We found that loggerheads bit at both large and small targets. 
They vigorously approached the small target with the mouth open, similar to the observations of juvenile loggerheads approaching hooked baits in the lab (Guzman 2008). Loggerheads approached the large target slowly, often while in a tucked position. This difference may have been due to the size of the jellyfish model, which was almost the same size or larger than most of the loggerhead turtles tested. When they bit it, they ignored the bell and attempted to feed only on the tentacles, effectively dealing with a smaller target. After the introduction of a food odor into the tank, loggerheads usually bit at the first object that moved; this was often their own reflection in the mirror present in the tank. It would be interesting to test this species with a smaller or mid-sized jellyfish model to see if their reactions differ.

We expected loggerheads to be much more successful at biting at targets than leatherbacks but found that this was not the case for the jellyfish model tests. Both species successfully bit at the target approximately half of the time. Comparing bite success with 2 different kinds of targets was not possible since the leatherbacks ignored the small target and because the parts of the jellyfish model that each species attempted to feed on differed. However, in broader view, interspecific comparison provides some insights into their effectiveness in apprehending the 'preferred' target type. Because leatherbacks often miss their food in the lab, we expected poor first bite success with the jellyfish model. Instead, we found they were at least as successful as loggerheads. This result may be due to the size of the jellyfish model, which was much larger and easier to see than the size food that the animals are accustomed to (approximately 8-10 $\mathrm{cm} \times 2 \mathrm{~cm}$ strips). Their food in the lab was much larger than the size of the small target. Similarly, loggerheads feed on food items that vary in shape but often are similar in size to the small target. Nevertheless, live jellyfish are readily eaten by loggerheads (as well as leatherbacks) when offered in the lab.

During bite accuracy trials, it was often necessary to initially jiggle the target to get the turtles' attention. We then tested if the turtles preferred a moving or stationary target. Loggerheads showed no preference for a moving target versus a stationary jellyfish model. With the small target, most bites were to the moving target. This behavior may be because the small target was comparable in size to their food. Their reaction to the jellyfish model was intriguing because most of the turtles assumed a defensive tuck position (Witherington 2002) when the jellyfish was introduced into the tank. The loggerheads were less likely to bite at the jellyfish model than the small target, and only the turtles that did not assume a tucked position bit the jellyfish model. Leatherbacks bit at a stationary jellyfish model much more often than a moving one. Typically, they would see the target move, watch until it stopped moving, and then approach it. The same behavior often was true for loggerheads; they would notice the jellyfish model while it was moving and then wait until it was stationary to bite. The fact that the target sometimes needed to move initially for the turtles to notice it and bite it is potentially significant. Perhaps once a prey odor is present, the prey needs to move for the turtles to locate it. Baited hooks are almost always exposed to moving water while suspended in water columns and would thereby provide both odor cues and visually alert sea turtles to the target. Due to the abundance of odors present in the areas where longline fishing occurs, bait movement may elicit feeding behavior in the turtles. A researcher was always standing next to the study tank during both control and experimental periods, therefore we do not believe the presence of a person moving the model in the water column caused any differences in behavior.

We make the assumption that the age of the turtles tested does not introduce significant bias to our results. All turtles in this study were between 2 and 7 wk of age. We noted a change in their feeding ability in the first few weeks and therefore did not test turtles until they were at least $2 \mathrm{wk}$ old. When turtles first begin eating, they will often crisscross their tank, searching for the food and take some time to orient and dive towards it. By the age of $2 \mathrm{wk}$, the turtles show maturation of their motor skills; they orient towards their food quickly and their movements are concise. Maturation of motor skills is well documented in young passerine birds (Barraud 1961) and shorebirds (Buckley \& Buckley 1974). Both of these studies showed that fledgling and juvenile birds spend more time searching for food and have to make more attempts to obtain food than adults. We cannot preclude the possibility that repeating these observations with turtles that are older might refine results of this study, especially if turtles further improve motor coordination with age and experience morphological growth changes in visual fields.

The results of this study are the first to show that juvenile leatherback sea turtles lack binocular vision and to our knowledge identify behavioral and morphological reasons that may explain bycatch differences between loggerhead and leatherback turtles. 
Acknowledgements. We thank the FAU Sea Turtle Research Lab undergraduate, graduate, and DIS students, as well as lab technicians and volunteers who assisted with the care of all animals used in this study. M. James provided the lion's mane jellyfish. The study was funded through the National Marine Fisheries (grant 140361) to J.W., the Gilbert Gordon Graduate Fellowship to N.W., and the Office of Undergraduate Research and Inquiry. S. Epperly, M. Salmon, L. Stokes, N. Thompson, and 3 anonymous reviewers provided helpful discussions that improved the manuscript. This research was permitted under USFWS permit TE056217-3 and FWC Marine Turtle Permit MTP-073. The study was approved by the FAU IACUC, A12-24.

\section{LITERATURE CITED}

Alfaro-Shigueto J, Mangel JC, Bernedo F, Dutton PH, Seminoff JA, Godley BJ (2011) Small-scale fisheries of Peru: a major sink for marine turtles in the Pacific. J Appl Ecol 48: 1432-1440

* Barraud EM (1961) The development of behaviour in some young passerines. Bird Study 8:111-118

Baum JK, Myers RA (2004) Shifting baselines and the decline of pelagic sharks in the Gulf of Mexico. Ecol Lett 7:135-145

Buckley FG, Buckley PA (1974) Comparative feeding ecology of wintering adult and juvenile royal terns (Aves: Laridae, Sterninae). Ecology 55:1053-1063

Cambiè G, Muiño R, Freire J, Mingozzi T (2012) Effects of small (13/0) circle hooks on loggerhead sea turtle bycatch in a small-scale, Italian pelagic longline fishery. Bull Mar Sci 88:719-730

* Casale P, Freggi D, Rocco M (2008) Mortality induced by drifting longline hooks and branchlines in loggerhead sea turtles, estimated through observation in captivity. Aquat Conserv 18:945-954

* Coelho R, Santos MN, Fernandez-Carvalho J, Amorim S (2015) Effects of hook and bait in a tropical northeast Atlantic pelagic longline fishery. I. Incidental sea turtle bycatch. Fish Res 164:302-311

* Constantino MA, Salmon M (2003) Role of chemical and visual cues in food recognition by leatherback posthatchlings (Dermochelys coriacea L). Zoology 106:173-181

Davis MW (2002) Key principles for understanding fish bycatch discard mortality. Can J Fish Aquat Sci 59: 1834-1843

Dodd CK Jr (1988) Synopsis of the biological data on the loggerhead sea turtle Caretta caretta (Linnaeus 1758). FWS88 (14). Florida Cooperative Fish and Wildlife Research Unit, Gainesville, FL

Donoso M, Dutton PH (2010) Sea turtle bycatch in the Chilean pelagic longline fishery in the southeastern Pacific: opportunities for conservation. Biol Conserv 143:2672-2684

Dunn DC, Boustany AM, Halpin PN (2011) Spatio-temporal management of fisheries to reduce by-catch and increase fishing selectivity. Fish Fish 12:110-119

Epperly SP, Watson JW, Foster DG, Shah AK (2012) Anatomical hooking location and condition of animals captured with pelagic longlines: the Grand Banks experiments 2002-2003. Bull Mar Sci 88:513-527

Fossette S, Gleiss AC, Casey JP, Lewis AR, Hays GC (2012) Does prey size matter? Novel observations of feeding in the leatherback turtle (Dermochelys coriacea) allow a test of predator-prey size relationships. Biol Lett 8: $351-354$
Fossette S, Witt MJ, Miller P, Nalovic MA and others (2014) Pan-Atlantic analysis of the overlap of a highly migratory species, the leatherback turtle, with pelagic longline fisheries. Proc R Soc B 281:20133065

FFoster DG, Epperly SP, Shah AK, Watson JW (2012) Evaluation of hook and bait type on the catch rates in the western North Atlantic Ocean pelagic longline fishery. Bull Mar Sci 88:529-545

Garrison LP (2005) Estimated bycatch of marine mammals and turtles in the U.S. Atlantic pelagic longline fleet during 2004. NOAA Tech Memo NMFS-SEFSC-531

* Gilman E, Huang HW (2017) Review of effects of pelagic longline hook and bait type on sea turtle catch rate, anatomical hooking position and at-vessel mortality rate. Rev Fish Biol Fish 27:43-52

Gilman E, Zollett E, Beverly S, Nakano H and others (2006) Reducing sea turtle by-catch in pelagic longline fisheries. Fish Fish 7:2-23

Gless JM, Salmon M, Wyneken J (2008) Behavioral responses of juvenile leatherbacks Dermochelys coriacea to lights used in the longline fishery. Endang Species Res 5:239-247

Guzman A (2008) Bite performance and feeding kinematics in loggerhead turtles (Caretta caretta) within the context of longline fishery interactions. MSc thesis, Texas A\&M University, College Station, TX

* Heaslip SG, Iverson SJ, Bowen WD, James MC (2012) Jellyfish support high energy intake of leatherback sea turtles (Dermochelys coriacea): video evidence from animalborne cameras. PLOS ONE 7:e33259

Kaplan IC (2005) A risk assessment for Pacific leatherback turtles (Dermochelys coriacea). Can J Fish Aquat Sci 62: 1710-1719

Kerstetter DW, Watson JW (2006) Pelagic longline fishing gear: a brief history and review of research efforts to improve selectivity. Mar Technol Soc J 40:6-11

Lewison RL, Crowder LB (2007) Putting longline bycatch of sea turtles into perspective. Conserv Biol 21:79-86

KLewison RL, Freeman SA, Crowder LB (2004a) Quantifying the effects of fisheries on threatened species: the impact of pelagic longlines on loggerhead and leatherback sea turtles. Ecol Lett 7:221-231

* Lewison RL, Crowder LB, Read AJ, Freeman SA (2004b) Understanding impacts of fisheries bycatch on marine megafauna. Trends Ecol Evol 19:598-604

* Lewison RL, Crowder LB, Wallace BP, Moore JE and others (2014) Global patterns of marine mammal, seabird, and sea turtle bycatch reveal taxa-specific and cumulative megafauna hotspots. Proc Natl Acad Sci USA 111: 5271-5276

* Lisney TJ, Theiss SM, Collin SP, Hart NS (2012) Vision in elasmobranchs and their relatives: 21 st century advances. J Fish Biol 80:2024-2054

* Luchetti A, Sala A (2010) An overview of loggerhead sea turtle (Caretta caretta) bycatch and technical mitigation measures in the Mediterranean Sea. Rev Fish Biol Fish 20:141-161

Marshall CD, Guzman A, Narazaki T, Sato K, Kane EA, Sterba-Boatwright BD (2012) The ontogenetic scaling of bite force and head size in loggerhead sea turtles (Caretta caretta): implications for durophagy in neritic, benthic habitats. J Exp Biol 215:4166-4174

McComb DM, Kajiura SM (2008) Visual fields of four batoid fishes: a comparative study. J Exp Biol 211:482-490

* Piovano S, Balletto E, Di Marco S, Dominici A, Giacoma C, Zannetti A (2004) Loggerhead turtle (Caretta caretta) 
bycatches on long-lines: the importance of olfactory stimuli. Ital J Zool 71(Suppl 2):213-216

Polovina JJ, Kobayashi DR, Parker DM, Seki MP, Balazs GH (2000) Turtles on the edge: movement of loggerhead turtles (Caretta caretta) along oceanic fronts, spanning longline fishing grounds in the central North Pacific, 19971998. Fish Oceanogr 9:71-82

Polovina JJ, Howell E, Parker DM, Balazs GH (2003) Divedepth distribution of loggerhead (Caretta caretta) and olive ridley (Lepidochelys olivacea) sea turtles in the central North Pacific: Might deep longline sets catch fewer turtles? Fish Bull 101:189-193

Salmon M, Wyneken J (1987) Orientation and swimming behavior of hatchling loggerhead turtles Caretta caretta L. during their offshore migration. J Exp Mar Biol Ecol 109:137-153

Santos MN, Coelho R, Fernandez-Carvalho J, Amorim S (2012) Effects of hook and bait on sea turtle catches in an equatorial Atlantic pelagic longline fishery. Bull Mar Sci 88:683-701

Shiode D, Hu F, Shiga M, Yokota K, Tokai T (2005) Midwater float system for standardizing hook depths on tuna longlines to reduce sea turtle by-catch. Fish Sci 71:1182-1184

Southwood A, Fritsches K, Brill R, Swimmer Y (2008) Sound, chemical, and light detection in sea turtles and pelagic fishes: sensory-based approaches to bycatch reduction in longline fisheries. Endang Species Res 5:225-238

Spotila JR, Reina RD, Steyermark AC, Plotkin PT, Paladino FV (2000) Pacific leatherback turtles face extinction. Nature 405:529-530

Stewart KR, LaCasella EL, Roden SE, Jensen MP, Stokes LW, Epperly SP, Dutton PH (2016) Nesting population origins of leatherback turtles caught as bycatch in the U.S. pelagic longline fishery. Ecosphere 7:e01272

Stokes LW, Hataway D, Epperly SP, Shah AK, Bergmann CE, Watson JW, Higgins BM (2011) Hook ingestion rates in loggerhead sea turtles Caretta caretta as a function of animal size, hook size, and bait. Endang Species Res 14:1-11

Stokes LW, Epperly SP, McCarthy KJ (2012) Relationship between hook type and hooking location in sea turtles

Editorial responsibility: Joanna Alfaro-Shigueto

(Guest Editor), Lima, Peru incidentally captured in the United States Atlantic pelagic longline fishery. Bull Mar Sci 88:703-718

Swimmer Y, Brill R (2006) Sea turtle and pelagic fish sensory biology: developing techniques to reduce sea turtle bycatch in longline fisheries. US Department of Commerce. NOAA Tech Memo NMFS-PIFSC-7

Swimmer Y, Gilman E (2012) Report of the Sea Turtle Longline Fishery Post-release Mortality Workshop, November 15-16, 2011. US Department of Commerce, NOAA Tech Memo NMFS-PIFSC-34

Swimmer Y, Gutierrez A, Bigelow K, Barceló C and others (2017) Sea turtle bycatch mitigation in US longline fisheries. Front Mar Sci 4:260

USFWS (1970) Leatherback sea turtle USFWS fact sheet. www. fws.gov/northflorida/SeaTurtles/Turtle\%20Factsheets/ leatherback-sea-turtle.htm (accessed 3 November 2019)

*Wallace BP, Heppell SS, Lewison RL, Kelez S, Crowder LB (2008) Impacts of fisheries bycatch on loggerhead turtles worldwide inferred from reproductive value analyses. J Appl Ecol 45:1076-1085

*Wallace BP, Kot CY, DiMatteo AD, Lee T, Crowder LB, Lewison RL (2013) Impacts of fisheries bycatch on marine turtle populations worldwide: toward conservation and research priorities. Ecosphere 4:40

*Wang JH, Boles LC, Higgins B, Lohmann KJ (2007) Behavioral responses of sea turtles to lightsticks used in longline fisheries. Anim Conserv 10:176-182

*Watson JW, Epperly SP, Shah AK, Foster DG (2005) Fishing methods to reduce sea turtle mortality associated with pelagic longlines. Can J Fish Aquat Sci 62: 965-981

*Witherington B (2002) Ecology of neonate loggerhead turtles inhabiting lines of downwelling near a Gulf Stream front. Mar Biol 140:843-853

Witzell WN (1999) Distribution and relative abundance of sea turtles caught incidentally by the U.S. pelagic longline fleet in the western North Atlantic Ocean, 19921995. Fish Bull 97:200-211

Zar JH (1998) Biostatistical analysis, 4th edn. Prentice Hall, Upper Saddle River, NJ

Submitted: March 13, 2019; Accepted: November 22, 2019 Proofs received from author(s): January 14, 2020 